\title{
A Revitalização de Centros Históricos na Perspectiva do Design: Estudo de Caso da Praia Grande em São Luís - MA
}

The Revitalization of Historical Centers from the Design Perspective: A Case Study of Praia Grande in São Luís - MA

ABREU, Eliane R.; Mestre; Universidade do Estado do Rio de Janeiro / Escola Superior de Desenho Industrial

elianerabreu@uol.com.br

GOMES, Luiz Vidal N.; Doutor; Universidade do Estado do Rio de Janeiro / Escola Superior de Desenho Industrial

luizvidalgomes@gmail.com

\section{Resumo}

O Centro Histórico da Praia Grande, em São Luís - MA, possui relevância cultural e histórica para a cidade, pois neste lugar aconteceu sua gênese. Fundada por franceses no século XVII, invadida por holandeses, retomada e colonizada por portugueses, o berço da cidade foi estabelecido e se desenvolveu economicamente, assim como sua arquitetura, através dos séculos. Na década de 1980 o Centro Histórico começou a ser revitalizado, após tantos anos de abandono resultado da decadência econômica do final do Século XIX. Em 1997, foi consagrado Patrimônio Histórico e Cultural da Humanidade pela UNESCO, mas novamente deu-se início a um novo processo de degradação. Assim, o objetivo desta pesquisa concentra-se na busca de parâmetros de design a serem adotados para uma nova intervenção, considerando aspectos configuradores da cultura local, de modo a valorizar o lugar impondo-Ihe a relevância que é pertinente.

Palavras Chave: Desenho Industrial; Revitalização Urbana; Desenho Urbano.

\begin{abstract}
The Historical Center of Praia Grande, in São Luís - MA, has cultural and historical relevance to the city, because in this place its genesis happened. Founded by French in the seventeenth century, invaded by Dutch, revived and colonized by Portuguese, the birthplace of the city was established and developed economically, as well as its architecture, through the centuries. In the 1980s, the Historic Center began to be revitalized, after so many years of abandonment resulting from the economic decadence of the late nineteenth century. In 1997, UNESCO was granted Word Heritage Site, but a new process of degradation began again. Thus, the objective of this research is focused on the search for design parameters, to be adopted for a new intervention, considering aspects that shape the local culture, in order to value the place by imposing the relevance that is pertinent.
\end{abstract}

Keywords: Industrial Design; Urban Revitalization; Urban Design. 


\section{Introdução}

O Centro Histórico da Praia Grande é um grande museu a céu aberto, apresentando um cenário da cidade de São Luís - MA caracterizado no séc. XVIII. Após sofrer por décadas com o descaso e abandono, foi revitalizado ao final dos anos de 1990 e agraciado com o título de Patrimônio Mundial.

Porém, devido a práticas de mal uso após a revitalização, esse importante local novamente enfrenta um período de degradação e esquecimento de seus significados para a identidade da cidade, visto se tratar de seu lugar de fundação. Apesar da restauração da maioria de seus casarões e edificações históricas, ruas, becos e vielas, e seus usos para moradia, comércio e sedes da administração pública estadual e municipal, estes não apresentam traços de conservação, resistindo aos rigores das intempéries, além da ação, muitas vezes inconsequente, do homem.

O ambiente urbano se apresenta carente de atrativos e infraestrutura, para ressaltar a riqueza do acervo material e imaterial presente no Centro Histórico, sendo utilizado apenas para eventos sazonais e isolados, atraindo a população como espectadores sem nenhuma percepção de valor sobre o lugar.

O objetivo da presente pesquisa de tese para doutoramento é identificar parâmetros aplicados ao projeto do design contemporâneo, para a definição de princípios a serem aplicados na revitalização de Centros Históricos, fazendo um estudo de caso para a Praia Grande, em São Luís - MA. Neste artigo são apresentados breve histórico e diagnóstico preliminar sobre a atual situação da Praia Grande, sendo realizada uma reflexão primeira, na perspectiva do design, sobre a revitalização dos valores implícitos no acervo histórico e cultural do lugar, através da concepção de projetos de urbanização abordando metodologias pertinentes ao campo de conhecimento do design. Finalizando com as considerações relativas às conclusões iniciais do trabalho, que não se apresentam como definitivas, visto serem falseáveis no decorrer da pesquisa.

A metodologia utilizada neste paper consistiu na pesquisa bibliográfica física e virtual, com auxílio de computador, coleta e análise de dados pertinentes à delimitação da pesquisa, para posterior paralelo entre as informações catalogadas, fornecendo substrato para reflexão e conclusões apresentadas.

\section{Centro Histórico da Praia Grande}

\subsection{Origem}

O bairro da Praia Grande, na época da fundação de São Luís - MA, em setembro de 1612, era uma vila erguida pelos franceses com o propósito da implantação da França Equinocial, nas novas terras descobertas ao sul da linha do equador. A gênese da ocupação francesa se dá com a construção de um forte militar, a Ponta do Rochedo, depois Forte de Saint Louis, em homenagem ao rei francês Luís XIII (LIMA, 1973), na foz dos rios Anil e Bacanga, onde hoje se encontra o Palácio dos Leões (figura 1), sede do governo estadual. (ANDRÉS, 1998) 
Figura 1 - Vista aérea do Palácio dos Leões

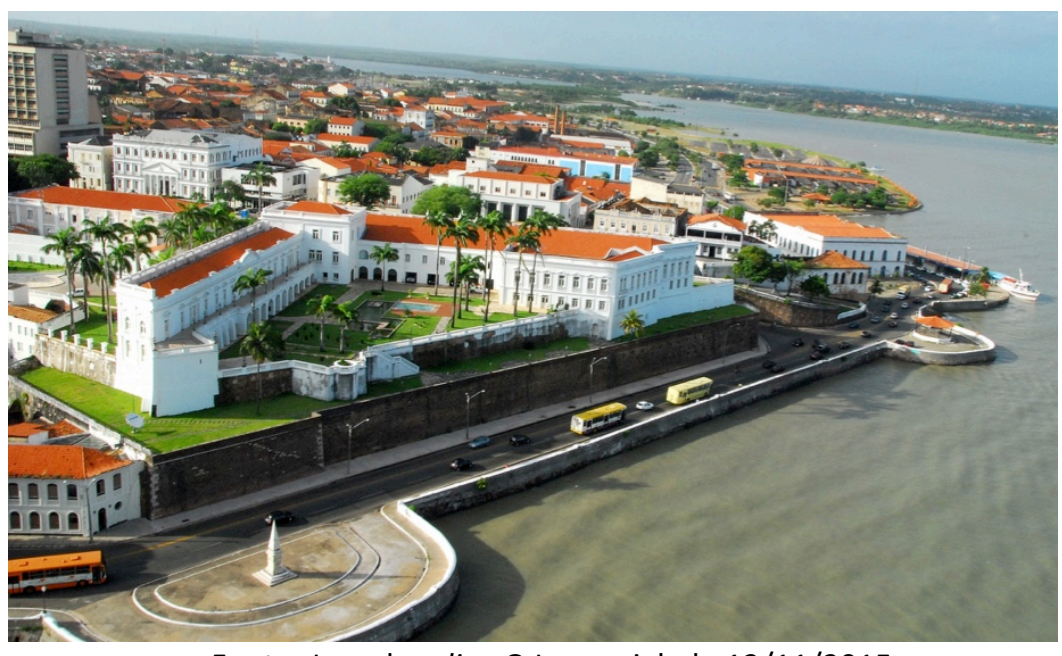

Fonte: Jornal on line O Imparcial, de 12/11/2015.

Porém, em 1615, na Batalha de Guaxenduba, os franceses são rendidos e expulsos pelo comandante português Jerônimo de Albuquerque. O forte Saint Louis passa a se chamar São Filipe, mas a povoação permanece com o nome de São Luís (PEREIRA, 1993). Assim, os portugueses retomam a província e iniciam uma nova ocupação organizada pelo engenheiro-mor do Brasil, Francisco Farias de Mesquita, adaptando o povoado embrionário já estabelecido pelos franceses, adotando uma traça de linhas ortogonais originando as ruas para circulação (SILVA F, 2008), herança dos processos construtivos renascentistas, estruturando urbanisticamente o lugar.

Holandeses invadem e tomam a Vila de São Luís em 1641, liderados por Maurício de Nassau. Durante o domínio fazem algumas obras na vila, como a construção da Igreja Matriz (onde hoje está o prédio do antigo Hotel Central), do Colégio de Nossa Senhora da Luz (atual Palácio do Arcebispado) e o Convento de Santa Margarida (depois Santo Antonio). Os holandeses foram expulsos por colonos portugueses, em 1644.

A Vila de São Luís se desenvolveu fora das muralhas do forte de São Filipe até meados do século XVII, através de construções de moradias e outras edificações, conforme mostra o mapa feito em 1647 (figura 2). Conforme a vila crescia, mais construções seguiam para o interior da ilha, até que em 1677, passou a status de cidade.

Figura 2 - Vila de São Luís, em 1647

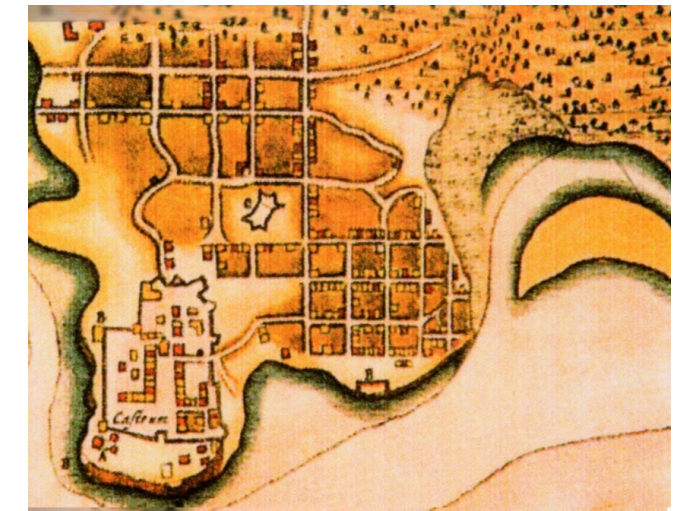

Fonte: São Luís - Ilha do Maranhão e Alcântara, 2008 
Fortes intervenções urbanas acontecem na cidade entre 1761 e 1779, decorrentes do desenvolvimento econômico do comércio, tais como: a modernização arquitetônica do antigo forte São Filipe, continuando a descaracterização da construção francesa, tornando-o Palácio do Estado; construção de um jardim pertencente ao largo do Palácio (Praça Pedro II, hoje), entre outras (ANDRÉS, 1998). Nesse momento começaram a ser construídos casarões e sobrados com gradis de ferro. A arquitetura local é marcada com traços barrocos, onde as residências dos comerciantes e fazendeiros exibiam seu poder econômico através dos seus casarões e sobrados (ABREU, 2011).

Olavo Pereira da Silva F. (1998) comenta que: "Na virada do Oitocentos, São Luís já não era uma tentativa de povoação, e sim um fenômeno cristalizado no expansionismo mercantilista do reino".

A cidade se encontrava em um período áureo de abundantes riquezas vindas do algodão, arroz e couro. José de Reinaldo Barros Ribeiro Júnior (1999) aborda o assunto em "Formação do Espaço Urbano de São Luís", afirmando que:

[...] somente no século XIX consolidou-se na cidade o sobrado azulejado e mirantado, em meio à abundante riqueza do algodão, arroz e couro. Foi em 1804, quando da primeira tentativa de calçar as ruas de São Luís, efetivando-se esta apenas três décadas após, por ocasião do calçamento das áreas nobres e do núcleo central da cidade. Com tais benfeitorias, o solo urbano adquire valor-de-uso e valor-de-troca. Cria-se o instituto de compra-e-venda. É o início da especulação imobiliária e segregação do espaço urbano. (RIBEIRO JÚNIOR, 1999)

\subsection{Processo de Abandono e Degradação}

Devido à efervescência do comércio, o consequente desenvolvimento da economia e um vislumbre promissor de futuro, era inevitável o aumento do índice demográfico na região. Em 1900, São Luís possuía uma população estimada em 29.475 habitantes, a antiga estrutura urbana já começava a não atender às demandas da população, que começava a enfrentar problemas com o lixo, o esgotamento sanitário, abastecimento de água, além da higiene das próprias habitações. A figura 3 mostra uma das principais ruas da Praia Grande, a Rua Portugal, em 1908. A imagem apresenta uma rua sem os requintes de outrora, com um caráter de abandono, apesar da opulência dos casarões coloniais desse logradouro.

Figura 3 - Rua Portugal, em 1908

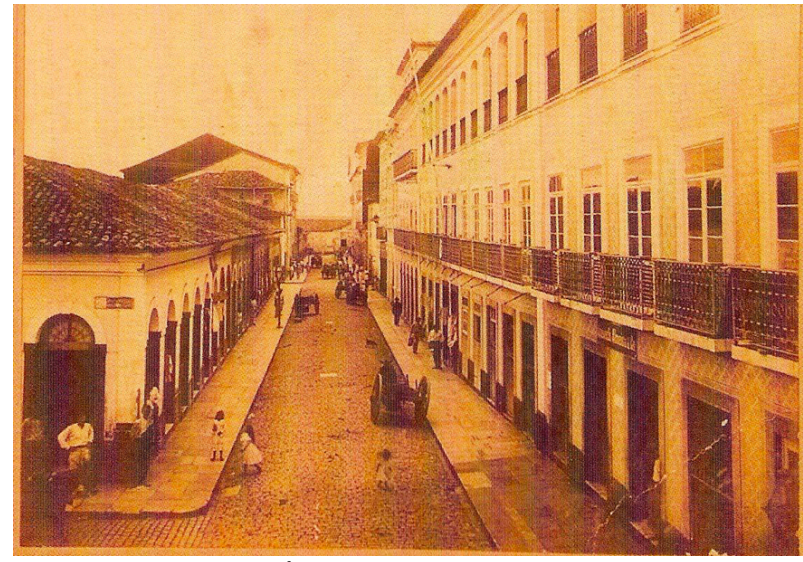

Fonte: Maranhão 1908 - Álbum Fotográfico, 2008. Galdêncio Cunha 
Devido às dificultosas condições de habitabilidade ocorreu, na primeira metade o século $\mathrm{XX}$, uma grande migração ao interior da llha onde estavam sendo construídas estruturas urbanas mais modernas e confortáveis para essa população de necessidades mais refinadas, seguindo um plano de remodelação da cidade, iniciado em 1940, por iniciativa do poder público com o objetivo de tornar a sede do estado mais moderna (LOPES, 2008).

Em 1974 é atribuído um Plano Diretor para a cidade que incentiva a verticalização das edificações, o que acelera o abandono da Praia Grande, tendo como consequência o esvaziamento do lugar, produzindo-se radicais mudanças no antigo ambiente de nobreza, que passa a abrigar oficinas, prostíbulos e galpões de serviços, além de contar com um número significativo de imóveis históricos relegados ao abandono, ou até mesmo ocupados de maneira inadequada por moradores de baixa renda, constituindo-se em mais cortiços.

Na década de 1980, as ruas recebiam um pesado e desordenado tráfego de automóveis e caminhões de grande porte, retirando o direito do pedestre de uma circulação segura nas calçadas, também em situação precária. Postes de concreto sustentavam uma rede caótica de fios elétricos e de telefonia, em meio a prédios antigos mal conservados e abandonados. A figura 4 mostra como era a circulação de veículos e a situação urbana do Largo do Comércio, principal ponto de circulação da Praia Grande, em 1985, e ao fundo, uma importante edificação histórica com mirante, escorada por estrutura de madeira, mostrando-se em avançado estágio de degradação.

Figura 4 - Largo do Comércio, em 1985

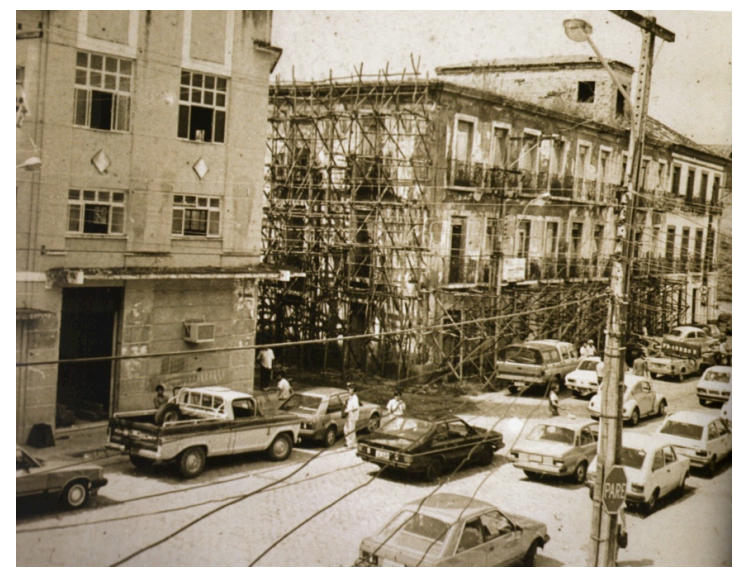

Fonte: São Luís - Reabilitação do Centro Histórico - Patrimônio da Humanidade, 2012

\subsection{Processo de Revitalização do Centro Histórico da Praia Grande}

As atenções ao acervo histórico da Praia Grande remonta à intervenção urbana ocorrida em São Luís, promovida pela administração estadual, com o intuito de modernizar a estrutura urbana da cidade. Essa ação causou controvérsia na opinião pública da época, devido a demolição de várias edificações antigas frente ao alargamento de eixos viários e alargamentos de ruas (VARGAS; CASTILHO, 2015).

O Centro Histórico de São Luís teve 1369 imóveis e logradouros tombados pelo patrimônio nacional em 1974, buscando reduzir os danos promovidos por tal intervenção, acompanhada pela administração municipal, que criou a Comissão do Patrimônio Artístico e Tradicional do Município, 
além de um decreto que impedia a demolição ou reforma de edifícios azulejados, ou não, com ou sem mirante (VARGAS; CASTILHO, 2015).

Um dos trabalhos de maior impacto sobre a preservação do acervo artístico e arquitetônico de São Luís, com aprofundamento científico e de produção de conhecimento a partir de bases metodológicas, originou-se do relatório do arquiteto português Alfredo Viana de Lima, então representante da Unesco, no final de 1973. O trabalho intitulava-se Rapport et propositions pour la conservation, récupération et expansion de São Luís/Maranhão (VARGAS; CASTILHO, 2015) e foi precursor na identificação das origens da arquitetura civil do acervo e a configuração urbana da cidade, a partir de modelos arquitetônicos aplicados na reconstrução de Lisboa, após o terremoto de 1755. O documento produzido abrangia uma visão de conjunto, descartando a ideia de monumentos isolados, permitindo estudos posteriores sobre a evolução urbana da capital maranhense, direcionando e escalonando prioridades para futuras intervenções (ANDRÉS, 2012).

Outro importante ator no processo de revitalização urbana da Praia Grande foi o arquiteto americano John Gisinger, através de sua proposta de ação para recuperação dos bens imóveis (ANDRÉS, 2012). O projeto elaborado pelo arquiteto foi amplamente discutido na 1a Convenção da Praia Grande, idealizado por Aluísio Magalhães, então presidente do Serviço do Patrimônio Histórico e Artístico Nacional - SPHAN (hoje o Instituto do Patrimônio Histórico e Artístico Nacional - IPHAN), promovido pelo governo do Estado, através da Secretaria de Planejamento - SEPLAN, com o apoio do SPHAN, envolvendo profissionais e experiências afins à preservação do patrimônio, em outubro de 1979. A partir desse evento, foi criado o Projeto Praia Grande para desenvolver e implementar o programa de revitalização, cujas ações foram norteadas por políticas de revitalização do acervo físico conforme se apresentava no passado, da infraestrutura, de ações sociais, culturais, educacionais, da economia, entre outras prioridades.

Após a revitalização do Centro Histórico da Praia Grande, tal como o Largo do Comércio mostrado na figura 5, comparada com uma foto de 1855, iniciaram-se as ações para incluir São Luís na lista do Patrimônio Mundial, que obtiveram resultados favoráveis e, em 1997, tornou-se Patrimônio Mundial da Humanidade. Segundo o International Council on Monuments and Sites ICOMOS (ANDRÉS, 2012):

O Centro Histórico de São Luís do Maranhão é um exemplo excepcional de cidade colonial portuguesa adaptada às condições climáticas da América do Sul equatorial e que tem conservado, dentro de notáveis proporções, o tecido urbano harmoniosamente integrado ao ambiente que o cerca.

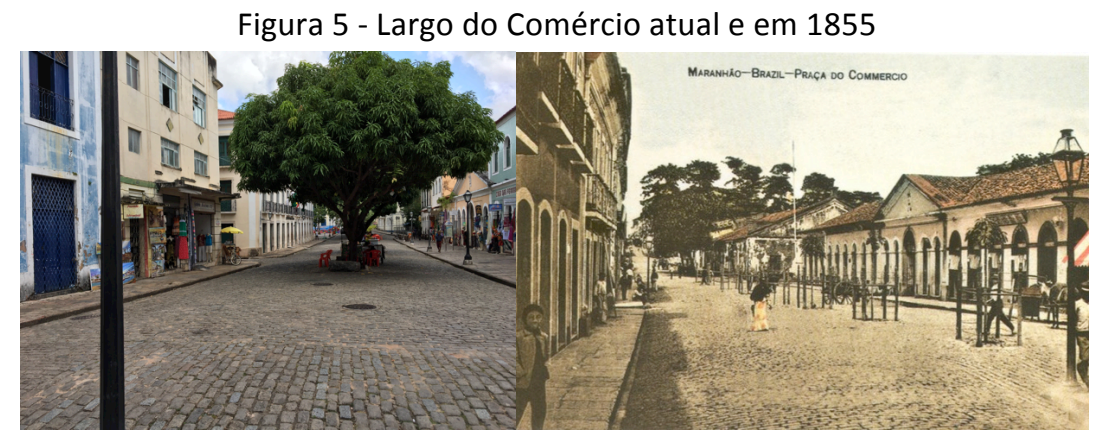

Fonte: Foto atual - acervo próprio; Foto de 1855 - Jornal online O Imparcial, de 08/09/2015. 


\subsection{Estado Contemporâneo de Preservação do Centro Histórico da Praia Grande}

Após São Luís ser incluída na lista de Patrimônio Mundial da UNESCO, o Centro Histórico da Praia Grande passou a ser um relevante ponto turístico, frequentado por turistas do Brasil e de outros países.

Porém, com o passar dos anos, os cuidados responsáveis pela preservação do acervo ficaram relegados ao acaso. Os maus tratos com o patrimônio tombado já se fazem evidentes: pichações, fachadas carentes de pintura, vegetação brotando em telhados, paredes com infiltrações, dentre outros problemas que denegrem esse espaço urbano histórico e cultural da capital maranhense. A figura 6 mostra os imóveis da rua Djalma Dutra pichados, à direita e sem cuidados, à esquerda.

Figura 6 - Imóveis da Rua Djalma Dutra

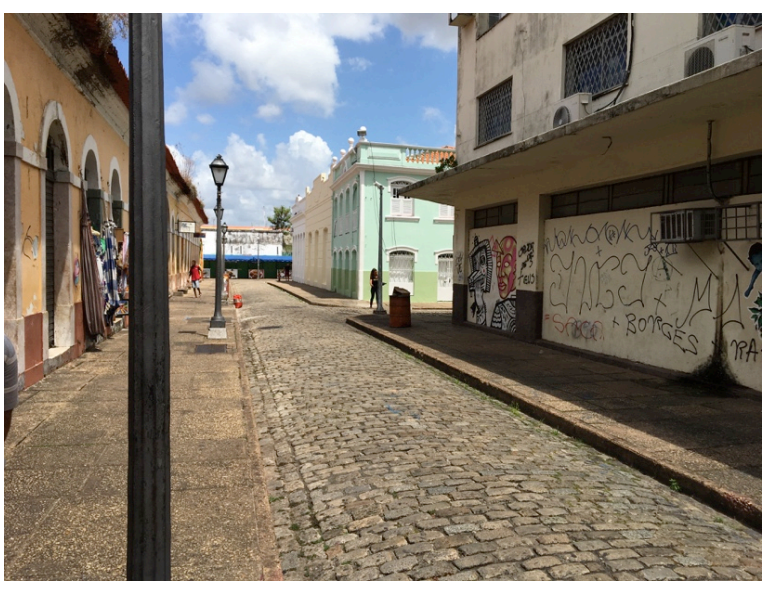

Fonte: Acervo pessoal (2017)

Outra questão levantada, é a arbitrariedade na exposição de produtos artesanais locais no espaço urbano, sendo colocados à revelia de qualquer organização estética nas fachadas históricas, assim como os engenhos publicitários desses comércios. (Figura 7)

Figura 7 - Fachadas de comércios com produtos

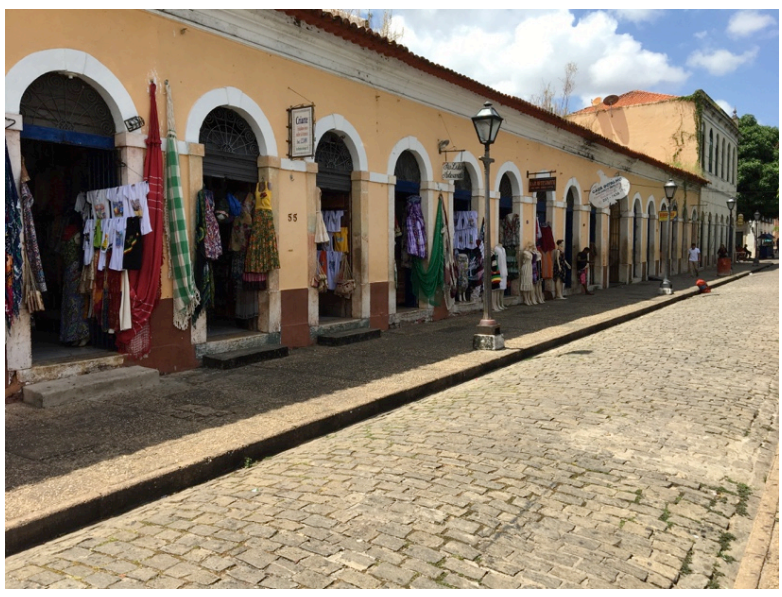

Fonte: Acervo pessoal (2017) 
Apesar da proibição de tráfego de veículos automotores em determinadas áreas, ainda há aqueles que burlam as leis e conduzem seus veículos pelas ruas estreitas do centro histórico, causando prejuízos imperceptíveis, porém nocivos à infraestrutura local. (Figura 8)

A área delimitada da pesquisa não possui sinalização urbana adequada que informe e conduza o turista pela Praia Grande, ou mesmo o cidadão local que não possua domínio espacial do Centro Histórico. Não apresenta equipamento urbano padronizado e necessário para as demandas da população, dentre outros problemas que afetam diretamente a saúde desse espaço urbano histórico, tão importante para a história e identidade cultural da cidade de São Luís.

Figura 8 - Trânsito indevido de veículo

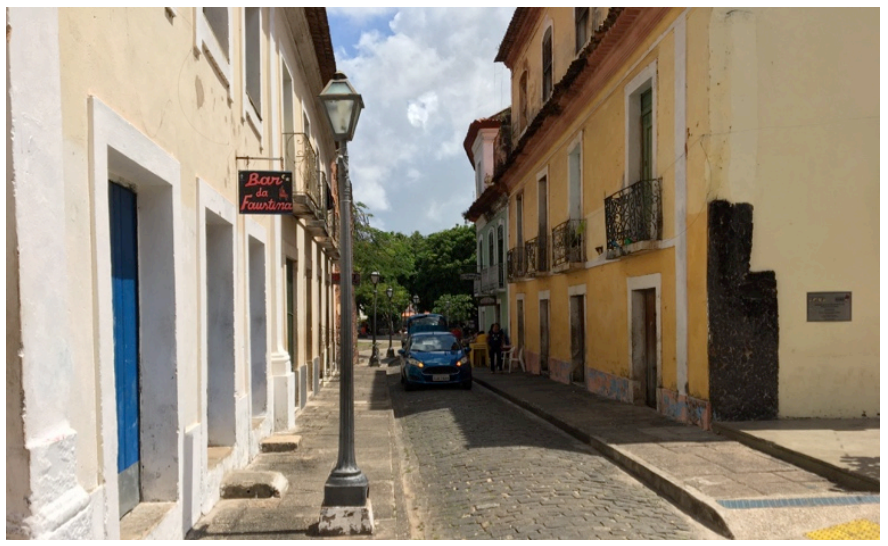

Fonte: Acervo pessoal (2017)

\section{Atuação do Design na Preservação de Lugares}

O ambiente urbano se configura por ser um espaço externo à individualidade de cada cidadão. Um ambiente democrático, de uso coletivo, capaz de comportar idiossincrasias pessoais e coletivas, mas representativo de uma identidade comum de seu respectivo agrupamento populacional. A gênese, os costumes, as perspectivas de futuro, são todos aspectos que caracterizam a formação e desenvolvimento de um lugar de uso comum da sociedade. Assim, pode-se observar que a população "consome" determinado meio urbano, por sua capacidade de suprir demandas que interessam ao usuário transeunte, tal como um produto projetado para atender as necessidades de determinado público-alvo.

Nesse contexto, o design urbano se faz presente abordando duas características de atuação que, para Guedes (2005), não são antagônicas mas apresentam certa distinção. A primeira maneira de compreender é como prática de projeto de "[...] todo um conjunto de produtos a serem utilizados no meio urbano, que não sejam edificações" (GUEDES, 2005). Essa perspectiva, conforme o autor, envolve toda uma classificação de mobiliário urbano, como: suportes de anúncios e sinalização, pequenas construções como banca de revistas, quiosques, caixas de banco, etc. Além de outros elementos observáveis nesse meio, por exemplo, fiação, cercas, hidrantes, guarda corpos, grades de proteção, dentre outros. Essa definição direciona a prática de projetação focada ao produto urbano, demandando um peculiar conjunto de conhecimentos, necessários a compreensão do ambiente que estão ou serão inseridos, tendo como objetivo uma "[...] visão sistêmica dos problemas existentes". (GUEDES, 2005)

A outra definição se apresenta mais abrangente, "[...] delimita uma área específica de 
conhecimento, que estuda de maneira geral a forma urbana e suas especificidades" (GUEDES, 2005). O autor ainda coloca que a tradução do termo em inglês urban design foi traduzido no Brasil como "desenho urbano". Uma tradução um tanto questionada por alguns autores, que interpretam o termo "desenho" como o restrito ato de representar algo graficamente, enquanto o termo "design" tem significado mais amplo, em inglês. Contudo, a terminologia "desenho urbano" é consensualmente utilizada no país desde a década de 1970.

Para Del Rio (1999):

O desenho urbano é o campo disciplinar que trata da dimensão físico-ambiental da cidade, enquanto conjunto de sistemas físico-espaciais e sistemas de atividades que interagem com a população, através de suas vivências, percepções e ações cotidianas.

Nessa perspectiva, a interação das pessoas com o meio urbano que frequentam se dá pelas atividades ali desenvolvidas, em espaços projetados para tal fim, criando um ambiente que estimula sua percepção e promove qualidade de vida.

Percebe-se a amplitude conceitual do desenho urbano, não se restringindo apenas ao projeto de equipamentos urbanos de forma isolada, mas como uma área de conhecimento atrelada ao design, com metodologia pertinente à prática projetual que, segundo Del Rio (1999), comporta quatro sub áreas, a saber:
a) Análise visual;
b) Percepção ambiental;
c) Estudos comportamentais;
d) Interpretações morfológicas.

Rigatti (1997) interpreta o desenho urbano como um projeto para uma determinada finalidade, no âmbito da cidade ou algum trecho dela.

\begin{abstract}
O desenho urbano deve ser compreendido nas suas dimensões de produto e processo. Como produto, constitui-se numa antevisão do que o espaço agenciado, pelo ato de vontade do desenhista, tem condições de vir a ser, contendo um caráter prescritivo. Como processo, implica em lidar com um conjunto de conhecimentos na busca de uma solução para um problema em especial. (RIGATTI, 1997)
\end{abstract}

$\mathrm{Na}$ perspectiva de Rigatti (1997) percebe-se a aderência da prática do design na conformação planejada de espaços públicos, a fim de proporcionar qualidade de vida à população, através do conforto físico, visual e emocional. Podendo ser ampliado para a valorização da identidade local, elencando tradições e significados que remetam à soluções sustentáveis de uso do lugar.

A abordagem de Rigatti (1997) é corroborada por Krucken (2009) quando esta afirma que o design contribui para "[...] dinamizar os recursos do território e valorizar seu patrimônio cultural imaterial [...]" reconhecendo e "tornando reconhecíveis valores e qualidades locais". Esses valores e qualidades são determinados, inclusive, por atributos apontados pela autora, como: (i) valor sentimental; (ii) certificação de origem e (iii) reconhecimento da comunidade/território onde se produz (KRUCKEN, 2009).

O lugar torna-se valorizado pela sedimentação de aspectos históricos, culturais, 
tradicionais e de identidade, que são revigorados após determinado período de exclusão, por algum motivo passado, ou esquecimento por parte das gerações mais contemporâneas. Essa forma de atuação do design produz uma cadeia sustentável, capaz de se estabelecer "[...] produtos de valor ao cliente e um design social para um sistema social." (KRUCKEN, 2009)

Entendendo o espaço urbano projetado, devidamente paramentado para o uso popular, como um produto concebido através da metodologia projetual pertinente ao design, é aceitável enquadrá-lo nas dimensões principais dos produtos, estabelecidas por Löbach (2001):

a) Prática ou funcional: envolve aspectos fisiológicos do uso;

b) Estética: abrange aspectos psicológicos da percepção;

c) Simbólica: envolve referências de formação pessoal, no uso.

Através dessas dimensões, os juízos de valores são ordenados e podem se mostrar flexíveis, de acordo com a utilidade, significado ou a relação com os demais objetos presentes em um sistema cultural. Esses valores têm a característica de possuírem forte teor afetivo, uma vez que sua concepção não é puramente racional. (MALAGUTI, 2009)

A afirmação de Cyntia Malaguti (2009) que "[...] os objetos e seus significados contribuem para a materialização do mundo culturalmente constituído, em uma dada sociedade [...]" corroboram a relevância social e cultural de um ambiente resultante de um projeto que envolva a identidade da comunidade local, em todos seus aspectos. Sobre isso, Bourdieu (2004) comenta:

Os símbolos são instrumentos, por excelência, da "integração social": enquanto instrumentos de conhecimento e de comunicação [...], eles tornam possível o consensus a cerca do sentido do mundo social, que contribui fundamentalmente para a reprodução da ordem social.

\section{Reflexões Preliminares sobre a Preservação do Centro Histórico da Praia Grande na Perspectiva do Design}

O Centro Histórico da Praia Grande se encontra em um preocupante estágio de negligência na preservação de seu acervo histórico, assim como no alcance de seu significado como referência cultural na cidade de São Luís.

O lugar demanda um processo de sedimentação da própria identidade, evidenciando sua importância como local de gênese da capital maranhense, com o propósito de reconhecimento da própria população transeunte, estimulando o sentimento de pertencer e ser protagonista da história em tempos contemporâneos.

As características de atuação do design, através do desenho urbano, propõe uma metodologia projetual que tem por objetivo a organização do espaço público, proporcionando um bem estar visual, físico e emocional, além da qualidade de vida aos que lá vivem, frequentam ou visitam, percebendo-se o contexto em que aquele espaço está inserido e sua relevância para o conjunto urbano que caracteriza a cidade.

O fato do Centro Histórico apresentar um acervo edificado e urbano impossibilitado de intervenções civis, devido estar protegido por leis e instituições que promovem sua preservação vislumbrando os arquétipos da sua história, não inviabiliza um estudo para inserção de elementos 
urbanos coadjuvantes ao ambiente, em um processo de simbiose buscando evidenciar características da identidade do lugar, sem comprometer a herança já estabelecida.

As sub áreas pertinentes à metodologia da prática projetual, estabelecidas por Del Rio (1999) se mostram conexas com aspectos a serem abordados para garantir a simbiose, e ainda, com as dimensões do produto apontadas por Löbach (2001), visualizando o lugar projetado como um produto, além de técnicas centradas no usuário, envolvendo a população local no processo criativo de concepção de ideias. Dessa forma, o campo de atuação do designer nesse processo de projetação de espaços, mostra-se de forma relevante para a ordenação e conjunção de dados e interpretações, pois a estrutura de valores orquestrada por cada indivíduo surge como o húmus para o alicerçamento de soluções sustentáveis, com significados expressivos, que incitam a própria população a fazer parte do processo de implementação e preservação, consciente das consequências de tais ações.

Somente a reconstrução do acervo material, com todas suas características formais replicadas como eram na época de sua origem, acompanhado de programas isolados para atração da população ao lugar para agir como espectadores, apenas tornará o sítio um cenário vazio de uma narrativa passada, desvinculada dos anseios contemporâneos de uma comunidade que não percebe os significados ali presentes, que estabeleceram o fundamento de sua própria identidade. Inicialmente, é perceptível a necessidade da projetação desse espaço urbano, de modo que haja uma integração sincera e sustentável entre o lugar e os cidadãos, designando-os agentes preservadores e propagadores da história e significados do lugar.

\section{Considerações Finais}

O Centro Histórico da Praia Grande é um espaço urbano de relevante importância para a identidade cultural da população ludovicense, com um rico acervo edificado, revitalizado, que lhe garantiu acesso à lista de Patrimônio Mundial. Porém, as más práticas de uso estão novamente deteriorando o lugar, tanto no aspecto físico de seu acervo, quanto no caráter imaterial de sua relevância para a cultura e identidade ludovicense.

Há uma percepção preliminar, através de dados da pesquisa, sobre a necessidade de implementação de ações, na perspectiva do design, com o intuito de evidenciar o valor e identidade desse sítio tombado, de forma sustentável, para reconhecimento e integração da própria população que frequenta o lugar. O desenho urbano se apresenta como tecnologia consistente, provida de metodologia projetual para efetuar as intervenções que aproximam o ambiente urbano de sua população nativa, fazendo-a pertencer ao lugar como protagonistas do processo de preservação.

A forma planejada de atuação do desenho urbano tem como objetivo proporcionar maior qualidade de vida à população, implementando artefatos responsáveis pelo seu conforto físico, visual e emocional, observando o contexto onde ocorrerá a inserção desses elementos, garantindo sincronia e harmonia com o meio. 


\section{Referências}

ABREU, Eliane Rodrigues. Rua Grande, um Resgate Histórico Através da Leitura Arquitetônica de suas Fachadas: Preservação x Desenvolvimento. 2011. 125p. Dissertação (Mestrado em Arquitetura) - Programa de Pós-Graduação em Arquitetura, Universidade Federal do Rio de Janeiro, Rio de Janeiro. 2011.

ANDRÉS, Luiz Phelipe de Carvalho Castro (coordenador geral). Centro Histórico de São Luís Maranhão: Patrimônio Mundial. São Paulo: Audichromo Editora. 1998.

ANDRÉS, Luiz Phelipe de Carvalho Castro. São Luís - Reabilitação do Centro Histórico: Patrimônio da Humanidade. São Luís: IPHAN, 2012.

BOURDIEU, P. O Poder Simbólico. Rio de Janeiro: Bertrand Brasil, 2004.

DEL RIO, Vicente; OLIVEIRA, Lívia de Oliveira. (Org.). Percepção Ambiental. A Experiência Brasileira. São Paulo. Studio Nobel. 1999.

GUEDES, João Batista. Design no Urbano: Metodologia de Análise Visual de Equipamentos no Meio Urbano. 2005. Tese de doutorado em Desenvolvimento Urbano - Universidade Federal de Pernambuco, Recife.

KRUCKEN, Lia. Design e Território: Uma Abordagem Integrada para Valorizar Identidades e Produtos. In: INTERNATIONAL SYMPOSIUM ON SUSTAINABLE DESIGN E SIMPÓSIO BRASILEIRO DE DESIGN SUSTENTÁVEL. 2., 2009, Anais... São Paulo: Universidade Anhembi Morumbi, 2009.

LÖBACH, B. Design Industrial: Bases para a Configuração de Produtos Industriais. São Paulo: Edgard Blücher, 2001.

LOPES, José Antonio de Viana (Coordenador Geral). São Luís, Ilha do Maranhão e Alcântara: Guia de Arquitetura e Paisagem. Ed. Bilíngue. Sevilla, 2008.

MALAGUTI, Cyntia. Design e Valores Materializados - Cultura, Ética e Sustentabilidade. In: DE MORAES, Dijon. KRUCKEN, Lia (Org.). Design e Sustentabilidade. Barbacena: EdUEMG, 2009.

PEREIRA, Epitácio Cafeteira A. Reviver. Brasília: Centro Gráfico do Senado Federal, 1993.

RIBEIRO JR., José de Reinaldo Barros. Formação do Espaço Urbano de São Luís. São Luís: Edições FUNC, 1999.

RIGATTI, Décio. Do Espaço Projetado ao Espaço Vivido. Modelos de Morfologia Urbana no Conjunto Rubem Berta. 1997. Tese de doutorado - FAU/USP, São Paulo.

SILVA F., Olavo Pereira da. Arquitetura Luso-Brasileira no Maranhão. Belo Horizonte: Formato, 2008.

VARGAS, Heliana Comin; CASTILHO, Ana Luisa Howard de. Intervenções em Centros Urbanos: Objetivos, Estratégias e Resultados. Barueri: Manole, 2015. 